\title{
Determination of Inorganic Ion in Biomaterials Using Capillary Ion Chromatography
}

\author{
Syukrya Ningsih \\ Department of Chemistry, Faculty of Sains and Technology, Sulthan Thaha Saifuddin \\ State Islamic University (UIN), Jambi, Indonesia \\ *E-mail: syukryaningsih@uinjambi.ac.id
}

\begin{abstract}
Ion Chromatography is widely used analytical technique for determination of anionic and cationic analytes in various sample matrices. Columns of flexible fused-silica tubing packed with commercially available materials have been prepared. The microcolumns were prepared in the laboratory from fused silica tubing TSKgel IC-Anion-PW $\mathrm{XL}_{\mathrm{XL}}(100 \mathrm{~mm}$ long $\mathrm{x} 0,320$ I.D). The parameters which affect the chromatographic retention behavior have been examined. For investigation of the optimum concentration of the eluent, the $\mathrm{NaCl}$ and $\mathrm{KCl}$ concentration was varied from 50 to $25 \mathrm{mM}$ and operated at eluent flow rate $3 \mu \mathrm{L} / \mathrm{min}$. The developed technique was successfully applied to the simultaneous determination of inorganic anions in real samples.
\end{abstract}

Keywords: micro packed column, ion chromatography, biomaterials

\section{Introduction}

Over the past decade, much research interest has focused on improving the efficiency of liquid chromatography column separation. Many column modifications were made to improve efficiency such as the pursuit of smaller column diameters in packed columns, monolithic columns, or open tubular capillary columns.[1-4] Ion chromatography is a suitable method for determining anions in solutions because it has high sensitivity and selectivity.[2,5] At the same time, ion chromatography is an efficient tool for the analysis of environmental samples because the relative concentrations of these inorganic anions can provide important information regarding the source of contamination. In addition, this method can give results in a short time with up to 10 anions specified in 20 minutes.[6]

In conventional ion chromatography, elution of ionic species usually involves the use of strong electrolytes with suppressed conductivity detection $[7,8]$. For anion separation, strong electrolytes such as inorganic salts or alkali hydroxides are often used to analyze various anionic species in ion chromatography applications [9]

It has been reported that flexible silica-silica capillary columns have been used in ion chromatography for several years. On the other hand, several studies using silica fusion columns have been reported in LC18 capillaries. [10] The column has high efficiency because of its smooth and inert surface. They are also very easy to handle and facilitate the adjustment of the coil diameter in the long column because of its flexibility and mechanical strength.

Capillary LC will save energy and waste. This will also improve the efficiency of LC columns and facilitate hyphenation with MS, which leads to the acquisition of more accurate analytical results in the near future. [11]. In this study, columns of flexible fused-silica tubing packed with commercially available materials have been prepared to determination of anion in biomaterials.

\section{Materials and Methods}

\subsection{Equipment}

A capillary ion chromatographic system was comprised of an MF-2 Micro Feeder equipped with an MS-GAN 050 gas-tight syringe $(0.5 \mathrm{ml}$; Ito, Fuji, Japan) as a pump, a model M435 microinjection 
valve (Upchurch Scientific, Oak Harbor, WA, USA) with a fused silica capillary loop as injection volume of $0.2 \mu 1$, a separation column, suppressor columns, two six-way switching valves, and a Tracedec contact less conductivity detector (Istech, Strasshof, Austria). The data were acquired by a Computer Aided Chromatography data processor. The separation column and suppressor columns were prepared by using fused silica capillary $(0.32 \mathrm{~mm} \mathrm{ID} \times 0.45 \mathrm{~mm}$ OD; GL Sciences $)$, and the column lengths were $10 \mathrm{~cm}$.

\subsection{Reagents and Materials}

Standard solutions were prepared by using deionized water. The eluent was prepared before use. Stock standard solutions for anions containing a mixture of interest ions were prepared. The standard solution of anions was prepared by dissolving $10 \mathrm{mM}$ of each $\mathrm{NaIO}_{3}, \mathrm{NaBrO}_{3}, \mathrm{NaBr}, \mathrm{NaNO}_{2}, \mathrm{NaNO}_{3}$, $\mathrm{NaI}$, and $\mathrm{NaSCN}$. All standard solutions were stored in polyethylene containers and kept under refrigeration at $4^{0} \mathrm{C}$.

\subsection{Preparation of column}

The separation column was prepared by using fused silica capillary, and packed with TSKgel ICAnion-PWXL (6 m particle diameter; Tosoh, Tokyo, Japan) by using a slurry packing method previously reported. The separation column was operated at room temperature (ca. $\left.25{ }^{\circ} \mathrm{C}\right)$. In addition, the stationary phases employed were taken out of the separation columns commercially available

\subsection{Preparation of biomaterials samples}

Biomaterials used are bagasse, sawdust and rice straw. Biomaterials as much as 5 grams are diluted with aqua regia as much as $50 \mathrm{~mL}$ for 24 hours, then filtered with a $2-\mu \mathrm{m}$ filter paper and then filtered with a $0.45-\mu \mathrm{m}$ membrane filter prior injection. All samples were then stored in a refrigerator at $4{ }^{\circ} \mathrm{C}$.

\section{Results and discussion}

\subsection{Optimal eluent concentration}

For investigation of the optimum concentration of the eluent, the eluent sodium chloride and potassium chloride concentration was varied from 50, 40, 30 and $25 \mathrm{mM}$.

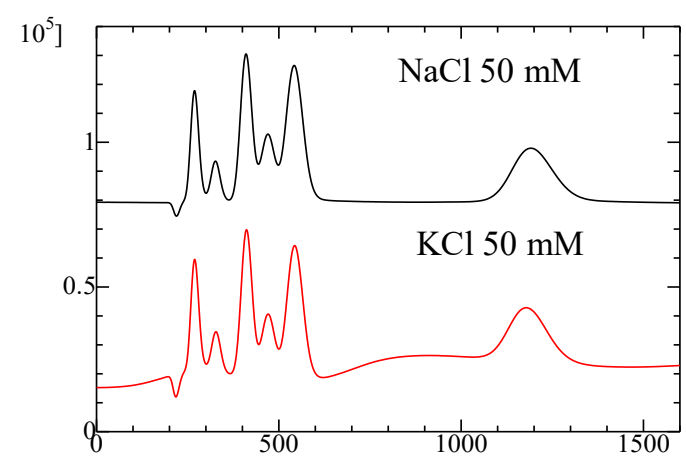

Figure 1. Chromatograms of optimal eluent concentration. TSKgel IC-Anion-PW $\mathrm{XL}$ columns ( $100 \mathrm{~mm}$ long x $0.32 \mathrm{~mm}$ i.d) is used and the eluent is $\mathrm{NaCl} 50 \mathrm{mM}, \mathrm{KCl}$

$50 \mathrm{mM}$. Wavelength of UV detection is $210 \mathrm{~nm}$. The flow rate is $3 \mu \mathrm{L} / \mathrm{min}$

Considering the retention time, peak shapes and peak resolution of the eluent was found the optimum concentration in $50 \mathrm{mM}$ for sodium chloride and potassium chloride. The sodium chloride concentration was varied from 50 to $25 \mathrm{mM}$. There is relationships between the logarithm of the retention factor of the analyte anions and logarithm of the eluent concenration were observed. 


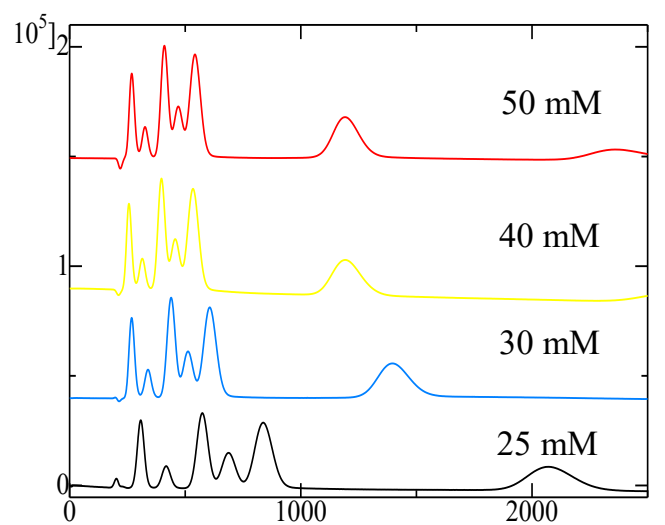

Figure 2. Chromatograms of sodium chloride concentration with variation of concentration is $50,40,30,25 \mathrm{mM}$. TSKgel IC-Anion-PW $\mathrm{XL}_{\mathrm{XL}}$ columns $(100 \mathrm{~mm}$ long $\mathrm{x}$ $0.32 \mathrm{~mm}$ i.d). Wavelength of UV detection is $210 \mathrm{~nm}$. The flow rate is $3 \mu \mathrm{L} / \mathrm{min}$. The sample is $\mathrm{IO}_{3}^{-}, \mathrm{BrO}_{3}^{-}, \mathrm{Br}^{-}, \mathrm{NO}_{2}^{-}, \mathrm{NO}_{3}^{-}, \mathrm{I}^{-}$, $\mathrm{SCN}^{-} 1 \mathrm{mM}$.

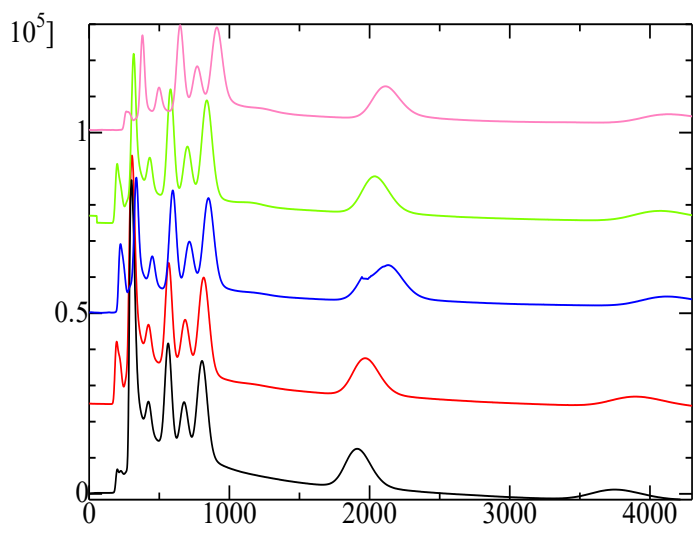

Figure 3. Repeatability Chromatogram of the standard. TSKgel IC-Anion-PW $\mathrm{XL}$ columns (100 mm long x $0.32 \mathrm{~mm}$ i.d) is used and the eluent is $\mathrm{NaCl} 25 \mathrm{mM}$. Wavelength of $\mathrm{UV}$ detection is $210 \mathrm{~nm}$. The flow rate is $3 \mu \mathrm{L} / \mathrm{min}$

\subsection{Application to real sample}

The optimum concentration of eluent is used on material samples consisting of bagasse, sawdust and rice straw. The eluent of $50 \mathrm{mM}$ sodium chloride showed good performance in term of selectivity and good peaks shapes for the determination of the above anions.

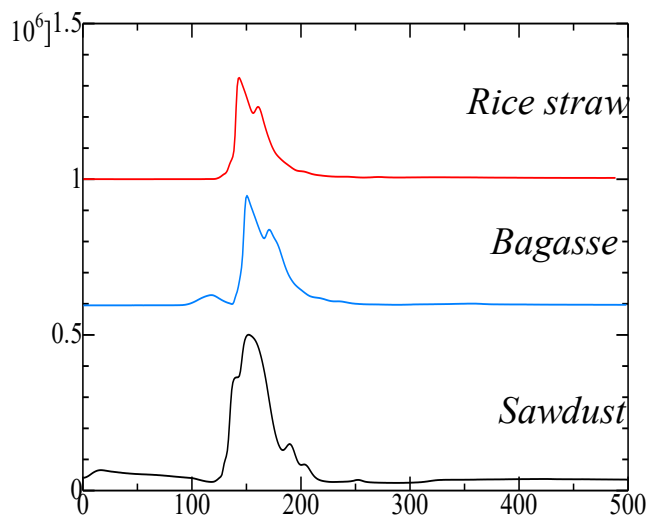

Figure 4. Chromatograms of organic compound of biomaterials. C18 columns (100 $\mathrm{mm}$ long $\mathrm{x} 0.32 \mathrm{~mm}$ i.d) is used and the eluent is Acetonitrile: water (70:10). Wavelength of UV detection is $210 \mathrm{~nm}$. The flow rate is $3 \mu \mathrm{L} / \mathrm{min}$. 


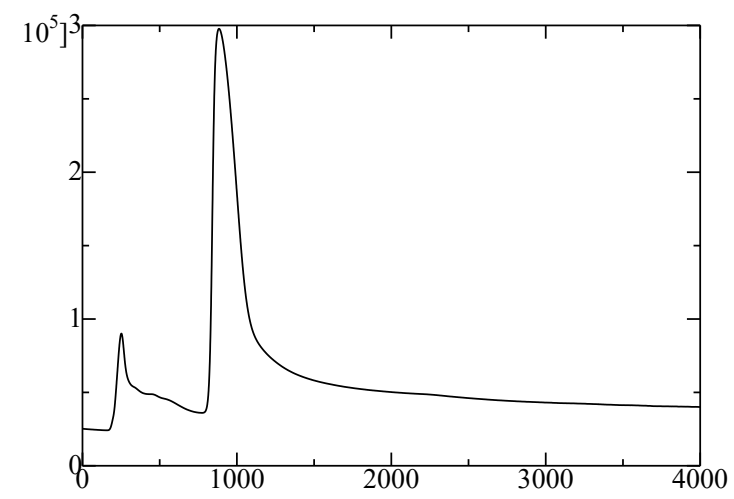

Figure 5. Chromatograms of biomaterial (sawdust). TSKgel IC-Anion$\mathrm{PW}_{\mathrm{XL}}$ columns $(100 \mathrm{~mm}$ long $\mathrm{x} 0.32 \mathrm{~mm}$ i.d) is used and the eluent is $\mathrm{NaCl}$ $50 \mathrm{mM}$. Wavelength of UV detection is $210 \mathrm{~nm}$. The flow rate is $3 \mu \mathrm{L} / \mathrm{min}$

\section{Conclusions}

The microcolumns were prepared in the laboratory from fused silica tubing TSKgel IC-Anion-PW $\mathrm{XL}_{\mathrm{XL}}$ (100 mm long x 0,320 I.D). The parameters which affect the chromatographic retention behavior have been examined. For investigation of the optimum concentration of the eluent, the $\mathrm{NaCl}$ and $\mathrm{KCl}$ concentration was varied from 50 to $25 \mathrm{mM}$ and operated at eluent flow rate $3 \mu \mathrm{L} / \mathrm{min}$. Considering the retention time, peak shapes and peak resolution of the eluent was found the optimum concentration to be $50 \mathrm{mM}$ for sodium chloride and potassium chloride. The developed technique was successfully applied to the simultaneous determination of inorganic anions in real samples.

\section{Acknowledgments}

This paper is an activity report of program short-term special research project trainee 2015, collaboration program of Gifu University and Andalas University. Thank you so much to my supervisor at Gifu University, Prof. Toyohide Takeuchi.

\section{References}

[1] Li, R.; Wang, Y.; Peng, M. H.; Wang, X.; Guo, G. Preparation and Application of Porous Layer Open Tubular Capillary Columns with Narrow Bore in Liquid Chromatography. Chin. J. Anal. Chem. 2017, 45, 1865-1873. DOI: 10.1016/S1872- 2040(17)61057-0

[2] Sestak, J.; Moravcova, D.; Kahle, V. Instrument Platforms for Nano Liquid Chromatography. J. Chromatogr. A. 2015, 1421, 2-17. DOI: 10.1016/j.chroma.2015.07.090.

[3] Collins, D. A.; Nesterenko, E. P.; Paull, B. Porous Layer Open Tubular Columns in Capillary Liquid Chromatography. Analyst. 2014, 139, 1292-1302. DOI: 10.1039/C3AN01869E.

[4] Hong, T.; Yang, X.; Xu, Y.; Ji, Y. Recent Advances in the Preparation and Application of Monolithic Capillary Columns in Separation Science. Anal. Chim. Acta. 2016, 931, 1-24. DOI: 10.1016/j.aca.2016.05.013.

[5] Jackson, P. E. Ion Chromatography in Environmental Analysis. In Encyclopedia of Analytical Chemistry; Meyers, R.A. Ed.; Chichester UK, 2000.

[6] States, S.; Cyprych, G.; Stoner, M.; Wydra, F.; Kuchta, J.; Monnell, J.; Casson, L. Marcellus Shale Drilling and Brominated THMs in Pittsburgh, PA Drinking Water. J. Am. Water Works Assoc. 2013, 105, 432-448.

[7] P. Haddad, P.N. Nesterenko, W. Buchberger, Recent developments and emerging directions in ion chromatography, J. Chromatogr. A 1184. 2008. 456-473.

[8] R. Michalski, Recent development and applications of ion chromatography, Curr. Chromatogr. 
1. 2014. 90-99

[9] H. Eghbali, C. Bruggink, Y. Agroskin, C.A. Pohl, S. Eeltink, Performance evaluation of ionexchangers chromatography in capillary format, J. Sep. Sci. 35. 2012. 3461-3468

[10] T. Takeuchi and D. Ishii. High-Performance Liquid Chromatography Using Flexible FusedSilica Micro-Packed Columns J. Chromatogr., 255 (1983) 349-3358

[11] Takeuchi, T. Capillary Columns in Liquid Chromatography. Anal Bioanal Chem. 2003. 375:2627. DOI 10.1007/s00216-002-1619-x 